\title{
Field portable XRF analysis of environmental samples
}

\author{
Dennis J. Kalnicky ${ }^{a}$, Raj Singhvi ${ }^{b, *}$ \\ ${ }^{a}$ Lockheed Martin Technology Services Group, Environmental Services/REAC, \\ 2890 Woodbridge Avenue, Edison, NJ 08837, USA \\ ${ }^{\mathrm{b}}$ US Environmental Protection Agency, Environmental Response Team Center, \\ 2890 Woodbridge Avenue, Edison, NJ 08837, USA
}

\begin{abstract}
One of the critical factors for successfully conducting contamination characterization, removal, and remedial operations at hazardous waste sites is rapid and appropriate response to analyze samples in a timely fashion. Turnaround time associated with off-site analysis is often too slow to support efficient utilization of the data. Field portable X-ray fluorescence (FPXRF) techniques provide viable and effective analytical approaches to meet on-site analysis needs for many types of environmental samples. Applications include the in situ analysis of metals in soils and sediments, thin films/particulates, and lead in paint. Published by Elsevier Science B.V.
\end{abstract}

Keywords: XRF; Field portable XRF; Environmental; In situ; Soil contamination; On-site

\section{Introduction}

One of the critical factors for successfully conducting extent of contamination, removal, and remedial operations at hazardous waste sites is rapid and appropriate analytical support to analyze site samples in a timely fashion. Historically, there have been problems obtaining high quality sample analysis results within a time frame necessary to support efficient utilization of the data. Field portable X-ray fluorescence (FPXRF) spectrometry has become a common analytical technique for on-site screening and fast turnaround analysis of contaminant elements in environmental samples. Applications include the in situ analysis of metals in soils and sediments, thin films/particulates, and lead in paint. FPXRF is a non-destructive analytical technique that allows both qualitative and quantitative analysis of the composition of a sample.

XRF spectrometry has been utilized in the laboratory for many years. Portable XRF technology has gained widespread acceptance in the environmental community as a viable

\footnotetext{
${ }^{*}$ Corresponding author. Tel.: +1-732-321-6761; fax: +1-732-321-6724.
} 
analytical approach for field applications due to the availability of efficient radioisotope source excitation combined with highly sensitive detectors and their associated electronics. While wavelength dispersive XRF has been the mainstay of laboratory instrumentation, energy dispersive XRF (EDXRF) is the technique of choice for field instrumentation primarily due to the ease of use and portability of EDXRF equipment. FPXRF instruments can provide both qualitative and quantitative analysis of environmental samples, and in some cases, without the need for site specific standards.

\section{Theory}

Atoms fluoresce at specific energies when excited by X-rays. Detection of the specific fluorescent photons enables the qualitative and quantitative analysis of most elements in a sample [1-3]. The mechanism for the X-ray fluorescence of an atom is illustrated in Fig. 1. An inner shell vacancy is created (by an incident X-ray photon or other phenomena) leaving an electron hole in the inner shell. An outer shell electron falls to fill the inner shell vacancy as the atom relaxes to the ground state. This process gives off photons with energy in the $\mathrm{X}$-ray region of the electromagnetic spectrum equivalent to the energy difference between the two shells.

Each atom has an X-ray line spectrum that consists of a series of discrete energies with intensities related to the probability that a particular transition will occur. The X-rays emitted

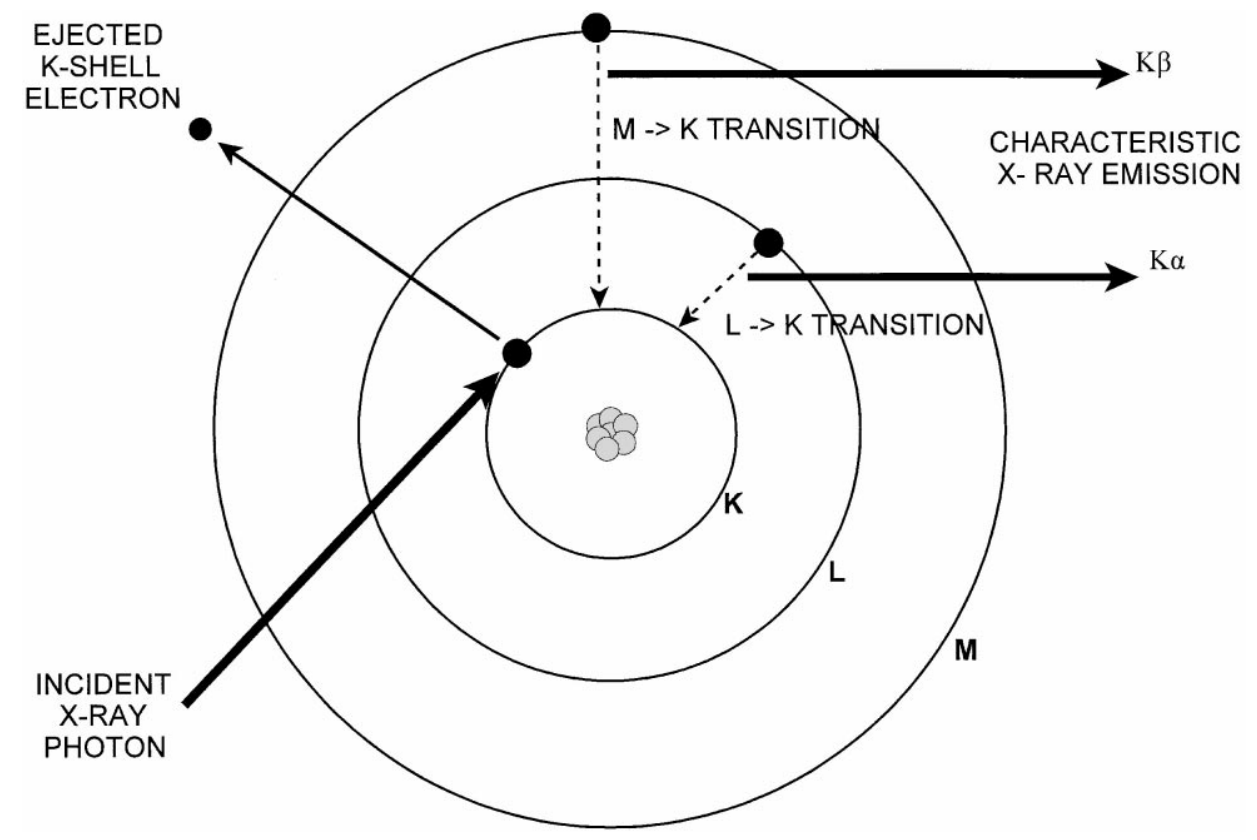

Fig. 1. Mechanism for X-ray fluorescence of an atom. 
are characteristic of the atom, and provide qualitative identification of the element. The photon energy of a spectral line is the difference in energy, $\Delta E$, between the initial and final levels involved in the electronic transition. Comparing the intensities of the X-rays from an unknown sample to those of suitable standards provides the basis for quantitative analysis of the element.

If the shell electron being replaced is a $\mathrm{K}$-shell electron, then the $\mathrm{X}$-ray emission is known as a K X-ray. Similarly, L-shell transitions produce L X-rays. X-ray spectral lines are grouped in series $(\mathrm{K}, \mathrm{L}, \mathrm{M})$. All lines in a series result from electron transitions from various levels to the same shell. For example, transitions from the L-and M-shells to the $\mathrm{K}$-shell provide spectral lines designated $\mathrm{K} \alpha$ and $\mathrm{K} \beta$, respectively. A spectrum of X-rays is generated by all the elements in the sample. Each element will have many characteristic lines in the spectrum, since a distinct X-ray will be emitted for each type of orbital transition.

\section{FPXRF analyzers}

Fig. 2 illustrates a block diagram of a typical XRF spectrometer. An excitation source (X-ray tube, radioisotope, etc.) is used to irradiate a sample which in turn fluoresces. The characteristic X-ray fluorescence is then detected and analyzed. The entire process is interfaced with a computer that provides general instrument control, data generation, and processing. Several different techniques may be used to induce fluorescence in a sample and to detect/analyze the characteristic X-rays given off by the sample.

EXCITATION SOURCE (RADIOISOTOPE)

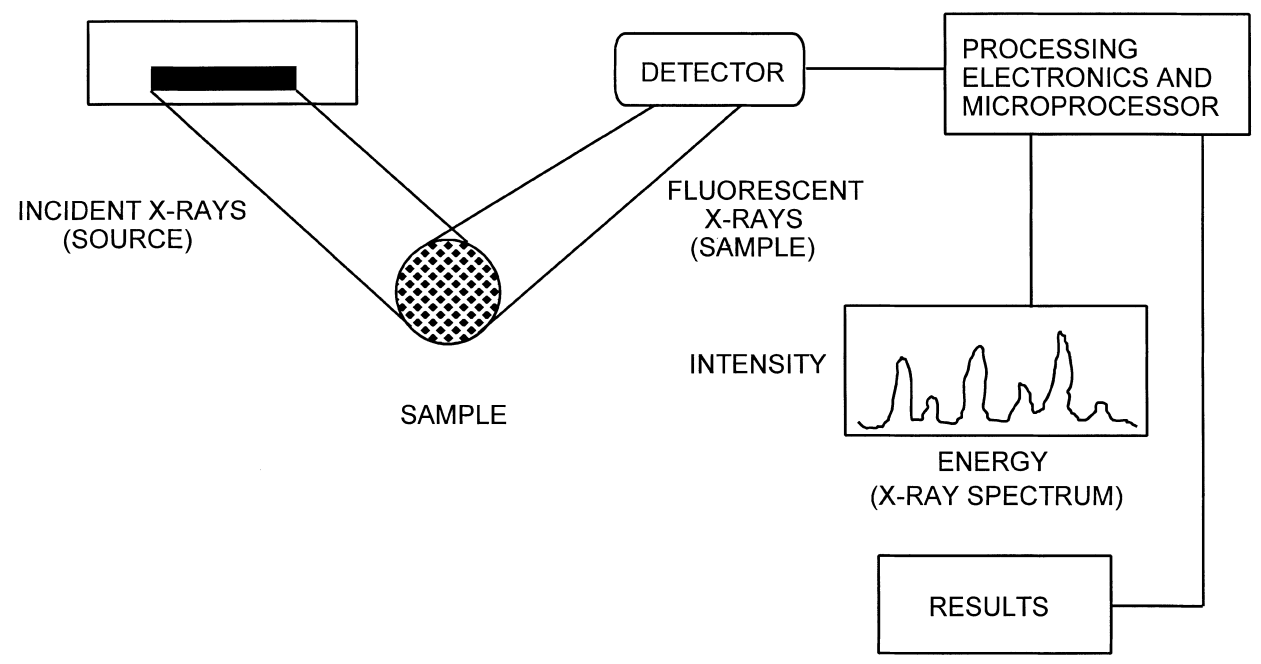

Fig. 2. Block diagram for a typical EDXRF spectrometer. 
Table 1

Commonly used radioactive isotopes for XRF analysis

\begin{tabular}{|c|c|c|c|c|}
\hline Isotope & Half-life & Useful radiation & Energy (keV) & $\begin{array}{l}\text { X-rays excited } \\
\text { efficiently }\end{array}$ \\
\hline $\mathrm{Fe}-55$ & 2.7 years & Mn K X-rays & 5.9 & $\mathrm{Al}-\mathrm{Cr}$ \\
\hline Co-57 & 270 days & $\begin{array}{l}\text { Fe K X-rays } \\
\gamma \\
\gamma \\
\gamma\end{array}$ & $\begin{array}{r}6.4 \\
14.4 \\
122 \\
136\end{array}$ & $<\mathrm{Cf}$ \\
\hline Cd-109 & 1.3 years & $\begin{array}{l}\text { Ag K X-rays } \\
\gamma\end{array}$ & $\begin{array}{l}22.2 \\
88\end{array}$ & $\begin{array}{l}\mathrm{Ca}-\mathrm{Tc} \\
\mathrm{W}-\mathrm{U}\end{array}$ \\
\hline Am-241 & 470 years & $\begin{array}{l}\text { Np L X-rays } \\
\gamma\end{array}$ & $\begin{array}{l}14-21 \\
26\end{array}$ & $\mathrm{Sn}-\mathrm{Tm}$ \\
\hline $\mathrm{Cm}-244$ & 17.8 years & $\begin{array}{l}\gamma \\
\text { Pu L X-rays }\end{array}$ & $\begin{array}{l}59.6 \\
14-22\end{array}$ & $\mathrm{Ti}-\mathrm{Se}$ \\
\hline
\end{tabular}

\subsection{XRF sources}

Various excitation sources may be used to irradiate a sample [1,3]. In a radioisotope source excited XRF analyzer, characteristic X-rays emitted from a sealed radioisotope source irradiate the sample. Alternately, an X-ray tube may be used to irradiate the sample with characteristic and continuum $\mathrm{X}$-rays. Some of the original application studies reported in the literature for transportable XRF analyzers utilized X-ray tubes as sources [4,5]. Shortly thereafter, radioisotope source FPXRF analyzers were evaluated for environmental applications [6].

Table 1 lists radioisotope sources typically used in FPXRF analyzers. The most commonly used sources include Fe-55, Co-57, Cd-109, and Am-241. Each of these gives off radiation at specific energy levels and, therefore, efficiently excites elements within a specific atomic number range. As a result, no single radioisotope source is sufficient for exciting the entire range of elements of interest in environmental analysis, and many instruments use two or three sources to maximize element range. The half-life of a source is important, especially for Fe-55, Co-57, and Cd-109 sources. With half-lives as short as 270 days, some means (usually electronic) must be provided to compensate for the loss in source intensity over time. These sources may have to be replaced after a few years when their intensity decreases to a level too low to provide adequate sensitivity for the elements of concern.

Intensity in X-ray spectrometry is always given in "counts" per unit time, that is, X-ray photons per unit area per unit time. The unit area is usually the useful area of the detector, which is constant for all measurements and, therefore, is normally not included in the X-ray intensity unit.

\subsection{Wavelength versus energy dispersion}

XRF analyzers are usually classified by wavelength or energy dispersion for X-ray line detection and analysis. Wavelength dispersion involves the separation of X-ray lines on the 
basis of their wavelengths, which may be accomplished with crystals (crystal dispersion), diffraction (diffraction dispersion), or spacial (geometric) dispersion. In energy dispersion, the separation of the X-ray lines is based on photon energies, and is accomplished by electronic dispersion with a pulse height analyzer. FPXRF analyzers typically employ energy dispersion for separation of X-ray lines. Wavelength is inversely proportional to energy and the conversion is [1,3], $E_{\mathrm{ev}}=12400 / \lambda$, where $E_{\mathrm{ev}}$ is the energy in electron volts and $\lambda$ is the wavelength in angstroms, $\AA$.

\subsection{Detectors}

The X-ray detector converts the energies of the $\mathrm{X}$-ray photons into voltage pulses that can be counted to provide a measurement of the total X-ray flux [2]. X-ray detectors are typically "proportional" devices where the energy of the incipient X-ray photon determines the size of the output voltage. Voltage discrimination via pulse height selection is used to select a narrow band of voltage pulses to pass to the scaling circuitry. A polychromatic beam of radiation incident upon the detector produces a spectrum of voltage pulses having a height distribution proportional to the energy distribution of the incident polychromatic beam. A multichannel analyzer is used to separate the spectrum of voltage pulses into narrow voltage bands for measurement of individual energies.

The three most common types of detectors are: the gas flow proportional detector, the scintillation detector, and the solid-state semiconductor detector. These detectors differ in resolution and analyte sensitivity. Resolution is the ability of the detector to separate $\mathrm{X}$-rays of different energies, and is important for minimizing spectral interferences and overlap. Semiconductor detectors have the best resolution and are preferred for FPXRF instruments. These detectors may require liquid nitrogen as a coolant or employ electronic cooling.

\subsection{FPXRF instrumentation}

All FPXRF analyzers utilize the basic components illustrated in Fig. 2. Some configurations incorporate a measurement probe connected to an electronics unit via a flexible cable. The probe houses the detector and radioisotope source(s), while the electronics unit contains the microprocessor and data processing electronics. Typically, the probe weighs $3-5 \mathrm{lb}$ and the electronics unit weighs 15-20 lb. Other FPXRF analyzers are contained in a single unit, and weigh less than $5 \mathrm{lb}$. Proper radiation shielding is provided by the manufacturer in accordance with applicable regulations governing manufacture and licensing of radioactive devices. The manufacturer also provides training in the safe and proper operation of the analyzer.

Table 2 lists representative FPXRF instrumentation. Some instruments provide dedicated element analysis (e.g. $\mathrm{Pb}$ in paint), while others provide a variety of elemental analyses depending on source and detector configuration. They generally are readily adaptable to field operations, though they may be limited by the power capacities of their batteries and the availability of liquid nitrogen. All provide a minimum of $8 \mathrm{~h}$ of field use with replacement of batteries. 
Table 2

Representative field portable XRF instrumentation for environmental analysis ${ }^{\mathrm{a}}$

\begin{tabular}{|c|c|c|c|c|c|c|}
\hline Manufacturer & Model number & Element range & Source & Detector & Utilities & Type \\
\hline Spectrace & $\begin{array}{l}9000 \\
9000 \mathrm{~Pb}\end{array}$ & $\begin{array}{l}\mathrm{S}-\mathrm{U} \\
\mathrm{Pb}\end{array}$ & $\begin{array}{l}\text { (3) ISO: Cd-109, Fe-55, Am-241 } \\
\text { ISO: Cd-109 }\end{array}$ & $\begin{array}{l}\mathrm{HgI} \\
\mathrm{HgI}\end{array}$ & $\begin{array}{l}\text { Battery } \\
\text { Battery }\end{array}$ & $\begin{array}{l}\mathrm{P} \\
\mathrm{P}\end{array}$ \\
\hline Metorex (Outokumpu) & $\begin{array}{l}\text { HAZMET } 940 \\
\text { XMET } 880 \\
\text { XMET } 920\end{array}$ & $\begin{array}{l}\mathrm{K}-\mathrm{U} \\
\mathrm{Al}-\mathrm{U} \\
\mathrm{Al}-\mathrm{U}\end{array}$ & $\begin{array}{l}\text { (2) ISO: Cd-109, Am-241 } \\
\text { ISO } \\
\text { ISO }\end{array}$ & $\begin{array}{l}\operatorname{SiLi}\left(\mathrm{N}_{2}\right) \\
\mathrm{PC}^{\mathrm{b}} \\
\operatorname{SiLi}\left(\mathrm{N}_{2}\right) / \mathrm{PC}\end{array}$ & $\begin{array}{l}\text { Battery } \\
\text { Battery } \\
\text { Battery } / 110 \mathrm{~V}\end{array}$ & $\begin{array}{l}\mathrm{P} \\
\mathrm{P} \\
\mathrm{P} / \mathrm{T}\end{array}$ \\
\hline NITON & $\begin{array}{l}\text { XL } 309 \\
\text { XL } 700 \text { series }\end{array}$ & $\begin{array}{l}\mathrm{Pb} \\
\mathrm{K}-\mathrm{U}\end{array}$ & $\begin{array}{l}\text { ISO: Cd-109 } \\
\text { (2) ISO: Cd-109, Am-241 }\end{array}$ & $\begin{array}{l}\text { SI PIN-diode } \\
\text { SI PIN-diode }\end{array}$ & $\begin{array}{l}\text { Battery } \\
\text { Battery }\end{array}$ & $\begin{array}{l}\mathrm{P} \\
\mathrm{P}\end{array}$ \\
\hline RMD & Lead Paint Inspector & $\mathrm{Pb}$ & ISO: Co-57 & Cd-telluride & Battery & $P$ \\
\hline SCITEC & MAP-3 & $\mathrm{Pb}^{\mathrm{b}}$ & ISO & $\mathrm{SiLi}$ & Battery & $\mathrm{P}$ \\
\hline PGT & XK-3 & $\mathrm{Pb}$ & ISO: Co-57 & $\mathrm{PC}$ & Battery & $P$ \\
\hline
\end{tabular}

${ }^{\mathrm{a}} \mathrm{ISO}=$ Isotope source (if isotope not listed, depends on probe configuration); $\mathrm{PC}=$ Proportional counter detector; $\mathrm{SiLi}$ and $\mathrm{HgI}=$ semiconductor detectors; $\mathrm{SiLi}$ $\left(\mathrm{N}_{2}\right)=$ liquid nitrogen cooled; $\mathrm{SiLi}$ (electric) = electrically cooled; $\mathrm{P}=$ portable; $\mathrm{T}=$ transportable.

${ }^{\mathrm{b}}$ May also be programmed for other selected elements. 


\section{Calibration and quantitation}

The definition of "quantitative" XRF analysis depends, to a large extent, on the application and intended use for the data. For environmental applications, FPXRF results are quantitative when measurement precision is within $20 \%$, and results are confirmed by an approved laboratory method [7]. Analysis of reference materials should produce results that are within $\pm 20 \%$ of the certified values for target elements that have concentrations more than 10 times the FPXRF detection limit. While this definition is much less stringent than that for classical laboratory XRF analysis, it is a viable approach for most FPXRF environmental applications.

\subsection{Factors affecting XRF calibration}

Quantitative application of XRF methods for environmental applications requires calibration of the XRF analyzer using standards with known compositions $[7,8]$. The calibration procedure compares X-ray intensity for target elements to known concentrations in standards to develop a quantitation model suitable for analyzing a given type of sample (e.g. soils, liquids, thin films). A number of factors that may affect XRF response must be considered during the calibration process: (1) detector resolution and its relationship to spectral interferences; (2) sample matrix effects; (3) accuracy and suitability of calibration standards; (4) sample morphology (particle size, homogeneity, etc.), and (5) sample measurement geometry.

Proportional counter detectors typically have significantly poorer resolution than solidstate semiconductor devices and, therefore, are less able to resolve X-ray spectral overlaps. Therefore, it may be impossible to calibrate certain element combinations solely due to detector limitations, for example, interfering $\mathrm{K} \mathrm{X}$-ray lines from neighboring elements. Furthermore, some X-ray line overlaps are so severe that even the best resolution obtained for semiconductor detectors on FPXRF systems is insufficient to separate them (e.g. As $\mathrm{K} / \mathrm{Pb} \mathrm{L}$ ), and residual error may persist in the spectral deconvolution techniques used to obtain net intensities for XRF calibration purposes.

Matrix effects arise from the impact that variations in concentrations of interfering elements have on the measured X-ray intensity of the target element. These effects produce non-linear intensity response versus target element concentration, and they appear as either X-ray absorption or enhancement phenomena. Most FPXRF analyzers provide means to correct for these effects when the application is calibrated. The severity of matrix effects and calibration method employed generally dictate the number of standards required to calibrate an application.

The standards selected to calibrate XRF applications must have accurately known concentrations for the target elements. The accuracy of the standards ultimately defines the best accuracy that can be expected for the XRF calibration model, and the measurement times necessary to achieve it. Calibration standards must also be representative of the matrix and target element concentrations that are to be analyzed. Sample morphology (particle size distribution, uniformity, heterogeneity, and surface condition) must be considered when calibrating environmental XRF applications. Standards should exhibit the same characteristics as the samples to be analyzed to produce a reliable calibration model. Sample placement 
Table 3

Comparison of XRF calibration methods

\begin{tabular}{ll}
\hline Empirical calibration & Fundamental parameters calibration \\
\hline $\begin{array}{l}\text { Site samples must be collected for use as standards and must } \\
\text { be certified by independent laboratory methods }\end{array}$ & $\begin{array}{l}\text { Must know or estimate 100\% of sample com- } \\
\text { position including unmeasured balance }\end{array}$ \\
$\begin{array}{l}\text { High costs associated with collection and analysis of site } \\
\text { samples and significant time to receive data back from the } \\
\text { laboratory }\end{array}$ & $\begin{array}{l}\text { Pure elements and/or readily available certi- } \\
\text { fied reference materials may be used as stan- } \\
\text { dards } \\
\text { XRF must be calibrated with site-specific standards prior to } \\
\text { project initiation }\end{array}$ \\
$\begin{array}{l}\text { No site-specific calibration is required; should } \\
\text { be applicable to any site with same sample } \\
\text { type }\end{array}$ \\
$\begin{array}{l}\text { All elements are included in the FP quanti- } \\
\text { tarrect for matrix effects }\end{array}$ & $\begin{array}{l}\text { need not bracket the levels at the site } \\
\text { FP model may require initial "fine-tuning" us- } \\
\text { ing certified reference materials }\end{array}$ \\
$\begin{array}{l}\text { Results based on a good calibration model will be accurate } \\
\text { and directly comparable to laboratory analysis }\end{array}$ &
\end{tabular}

is a potential source of error, since the X-ray signal is sensitive to measurement geometry and decreases as the distance from the excitation source increases. This error is minimized by maintaining the same source/sample geometry for all calibration standard and sample measurements.

\subsection{Calibration methods}

There are two major approaches for calibrating FPXRF applications. The empirical approach relies on a suite of site (or "typical") standards and regression mathematics to generate a site-specific calibration for elemental response and matrix effects. The fundamental parameters (FP) approach utilizes X-ray theory to mathematically pre-determine interelement matrix effects combined with pure element or known standard intensity responses to develop a quantitative algorithm for a specific sample type. FP methods provide multi-site capabilities by eliminating the requirement for site-specific standards. A comparison of site-specific and FP calibration methods is given in Table 3.

\subsubsection{Empirical calibrations}

Empirical calibrations are typically based on a set of previously collected site-specific calibration standards (SSCS) that have been analyzed by reliable independent laboratory methods [8-10]. They must be representative of the matrix and target element concentration ranges at the site. Standards must bracket the full range of target element and interfering matrix element concentrations, and must reflect variations in element ratios to produce a representative calibration model. The highest and lowest concentrations in the SSCS set define the calibration range. Samples used to generate the calibration must be prepared in the same way as samples that will be analyzed at the site. The SSCS set should include several samples with concentrations near the critical concentration of concern, i.e. the action level, to improve the accuracy of the empirical calibration model. The greater the knowledge about the sample matrix (how it varies at the site), the more representative the calibration model is and, therefore, the more accurate the results. 
Typical models used for empirical calibration are described elsewhere [3,9,10]. A minimum of 5-10 samples are needed to generate a simple linear model for a single analyte when interelement matrix effects are not significant. As the number of elements analyzed increases, more calibration samples are required to adequately characterize target element concentration ranges and correct for interelement matrix effects. For some applications, it may be necessary to produce more than one calibration model to maintain linearity over the concentration ranges in question. If the sample matrix varies significantly, a calibration model should be generated for each matrix type present at the site to provide better characterization.

In some cases, taking out the ratio of the analyte intensity to the scattered X-rays from the source (backscatter) may be useful to correct for matrix effects, because backscatter intensity is proportional to the average composition of the sample. The ratio technique may also be useful for generating non-site-specific empirical models provided a sufficient number of standards "typical" of the sample matrix are available. For example, analysis of metal contaminants in soils where backscatter may provide information on the average composition of the soil sample.

\subsubsection{Fundamental parameters calibrations}

FP techniques have been understood and commonly utilized on laboratory XRF systems for many years to analyze a wide variety of materials $[1-3,11,12]$. Historically, FPXRF instruments that have been used for environmental applications have relied upon site-specific calibration methods that have not been useful for more than one site and/or sample matrix. With the availability of field portable computing power, the FP approach is valid for FPXRF analyzers and provides multi-site capabilities by eliminating the requirement for site-specific standards. However, uncertainties in the data used to generate theoretical coefficients may lead to errors and biases in FP analytical models based on them. Therefore, adjustments based on certified reference materials may be necessary to produce reliable results. The resultant application is, in principle, suitable for analysis of target elements for a given sample type (soil, water, oil, thin films, etc.) at any site.

The FP approach utilizes theory to pre-determine interelement coefficients rather than empirical methods that require matrix specific calibration standards (see Table 3). Background and overlap corrected net intensities are converted into concentrations by an appropriate FP algorithm. For accurate results with FP, the entire sample composition must be known. Many elements found in environmental samples (e.g. C, O, N, Si) cannot be measured with field-portable XRF instruments, therefore, assumptions must be made about the unmeasured balance of the sample. In some cases, the composition of the unmeasured balance is well defined, and can be included as part of the FP calculation. Furthermore, it may also be possible to determine the average composition of the unmeasured balance based on backscatter X-rays from the radioisotope source used for sample excitation. The lower the average atomic number of the sample, the higher the intensity of the incoherently scattered peak (Compton peak). This also applies to a lesser degree to the coherently scattered peak (Raleigh peak). The ratio of these two peaks (Compton/Raleigh) is proportional to the average atomic number and, therefore, the average composition of the sample.

Several criteria must be met to successfully apply FP techniques in XRF analyses [13]: (1) all significant sample elements must be considered; (2) $100 \%$ of the sample 
composition (measured plus unmeasured balance) must be known to theoretically calculate FP coefficients; (3) the typical composition of the sample including the unmeasured balance must be known; (4) overlap spectra and pure (100\%) intensities for all measured elements are required, and (5) the final FP model must be verified and optimized as necessary using certified standards of the same matrix type as the samples to be analyzed. Furthermore, since XRF measures total concentrations of the elements of interest, the standards used to optimize FP models should be certified based on total elemental analysis. Because $100 \%$ of the sample composition must be considered in the FP calibration approach, different models need to be used for samples/matrices with major differences in the non-XRF elements (unmeasured balance). Therefore, a model for soils and sediment may not be applicable for sludge and industrial waste.

FP algorithms may be applied in a rigorous fashion or as "alpha coefficients" models $[8,13]$. The rigorous approach is generally used for laboratory XRF analyzers to provide analysis capabilities for a wide variety of sample types. The alpha coefficients approach is better suited to FPXRF analyzers, where the FP coefficients (for a specific sample type) are pre-determined using an external PC, and then downloaded into the FPXRF analyzer memory.

The main benefit of using FP techniques is that as little as one standard is required to calibrate the XRF system for quantitative analysis. On the other hand, the entire composition $(100 \%)$ of the standard(s) must be known or accurately estimated to successfully calibrate the FP algorithm. Other advantages include: (1) no site-specific calibration is required; (2) minimal operator training is required; (3) all relevant elements are included in the concentration calculation, and (4) the FP model is applicable to any site (not site-specific) for a given sample type (e.g. soils).

\subsubsection{Thin sample calibrations}

Laboratory XRF systems have been used for many years to analyze environmental thin-specimen samples [14]. The use of portable XRF analyzers for screening air monitoring filters has been reported [15]. Calibrating XRF analyzers for thin sample applications (e.g. particulates on filters, dust on wipes, lead in paint, etc.) is generally a less difficult task than that for bulk samples. This is because interelement matrix effects are negligible for all but the lowest energy X-ray lines (i.e. less than $5 \mathrm{keV}$ ), therefore, a linear relationship exists between the fluorescent intensity of the element in the film and the mass per unit area of that element $[16,17]$. The XRF calibration is typically accomplished using empirical methods and standards with known mass loading (mass per unit area). However, FP approaches have also been used. Problems associated with thin sample analyses include self-absorption in particles with low energy X-ray lines (particle size effects) and substrate interference effects. Both of these effects require application of empirical or theoretical correction factors in addition to the linear response models based on thin sample calibration standards.

Portable XRF lead-based paint analyzers have typically been pre-calibrated by the manufacturer using certified lead-in-paint standards. The XRF measurement is susceptible to variable scattering of the source $\mathrm{X}$-rays from the substrate material beneath the paint layers. Most lead-in-paint XRF analyzers provide corrections for substrate scattering; however, the corrections may not be effective in all cases. Furthermore, depending on which lead X-ray 
line is measured (K-shell or L-shell), the analysis may be affected by the paint matrix and the number of overlying and underlying (wallbase) layers.

Thin sample calibration standards for metals on filter media and lead-in-paint are available from NIST [18]. Leaded film standards are also commercially available [19].

\section{Detection limits}

Detection limits (DLs) for XRF analysis are both element and matrix dependent, and most elements are detectable below typical site action levels. XRF DLs are dependent on analysis time; longer analysis times provide lower DLs. While XRF is a relatively fast technique, the longer analysis times required for improved DLs impact the total number of samples analyzed during a specific time period.

\subsection{Calculation of detection limits}

Several methods may be used for the determination of the detection limit (DL) for EDXRF analysis. A widely accepted method states that the DL is "that amount of analyte that gives a net line intensity equal to three times the square root of the net background intensity for a specified counting time, or in statistical terms, that amount that gives a net intensity equal to three times the standard counting error of the background intensity" $[1,20]$. This definition can be expressed as

$$
\mathrm{MDA}=\left(\frac{3}{m}\right)\left(\frac{I_{\mathrm{B}}}{T_{\mathrm{B}}}\right)^{1 / 2}
$$

where, MDA is minimum detectable amount, $I_{\mathrm{B}}$ the background count rate (counts/s), $T_{\mathrm{B}}$ the background count time (s), and $m$ the sensitivity (net counts/s per unit concentration). Detection capabilities improve (decrease) as counting time increases, as background decreases, and as sensitivity increases. The DL may also be defined in terms of the precision of repeat measurements on a standard sample. Once an analyzer has been calibrated, intensity is converted to concentration, and variations in X-ray intensity and all other error parameters are reflected in the variation of the concentration. The US EPA [21] recommends that the DL be determined by the measurement of a sample that has a concentration of analyte close to the expected DL. The standard deviation of non-consecutive replicate measurements multiplied by the rounded Student's $t$-factor is the recommended estimation of the method detection limit (MDL)

$$
\mathrm{MDL}=3 \sigma
$$

where $\sigma$ is the standard deviation for the replicates, and the Student's $t$-factor is approximately equal to three. This method provides a realistic DL value, because all parameters (e.g. time, sample handling errors, etc.) that affect the measurement are included. 
Table 4

Comparison of DLs $(\mathrm{mg} / \mathrm{kg})$ in relationship to measuring times

\begin{tabular}{|c|c|c|c|c|c|c|c|}
\hline \multirow[t]{2}{*}{ Element } & \multicolumn{6}{|c|}{ Measuring time (s) } & \multirow[t]{2}{*}{ Average concentration ${ }^{\mathrm{a}}$} \\
\hline & 15 & 30 & 60 & 120 & 240 & 480 & \\
\hline $\mathrm{K}$ & 1573 & 1402 & 745 & 667 & 285 & 362 & 14278 \\
\hline $\mathrm{Ca}$ & 1369 & 882 & 681 & 500 & 265 & 211 & 21187 \\
\hline $\mathrm{Ti}$ & 630 & 574 & 445 & 321 & 129 & 120 & 4155 \\
\hline $\mathrm{CrLO}^{\mathrm{b}}$ & 465 & 252 & 173 & 151 & 117 & 53 & $-56^{c}$ \\
\hline $\mathrm{CrHI}^{\mathrm{b}}$ & 817 & 516 & 562 & 348 & 137 & 188 & 29 \\
\hline $\mathrm{Mn}$ & 1217 & 757 & 756 & 248 & 313 & 225 & 634 \\
\hline Co & 705 & 567 & 555 & 406 & 252 & 274 & 243 \\
\hline $\mathrm{Ni}$ & 211 & 140 & 121 & 73 & 84 & 49 & 18 \\
\hline $\mathrm{Cu}$ & 187 & 148 & 83 & 69 & 32 & 17 & 17 \\
\hline $\mathrm{Zn}$ & 160 & 120 & 46 & 42 & 45 & 32 & 119 \\
\hline As & 94 & 42 & 52 & 30 & 36 & 17 & 17 \\
\hline $\mathrm{Se}$ & 95 & 25 & 34 & 26 & 12 & 6 & $-15^{\mathrm{c}}$ \\
\hline $\mathrm{Sr}$ & 104 & 41 & 34 & 34 & 18 & 15 & 351 \\
\hline $\mathrm{Zr}$ & 54 & 45 & 22 & 14 & 10 & 7 & 196 \\
\hline Mo & 14 & 9 & 7 & 6 & 3 & 2 & 3 \\
\hline $\mathrm{Hg}$ & 95 & 92 & 77 & 56 & 23 & 17 & $-21^{\mathrm{c}}$ \\
\hline $\mathrm{Pb}$ & 61 & 41 & 42 & 22 & 12 & 11 & 26 \\
\hline $\mathrm{Rb}$ & 52 & 32 & 18 & 14 & 9 & 6 & 51 \\
\hline $\mathrm{Cd}$ & 319 & 242 & 105 & 88 & 93 & 46 & 55 \\
\hline $\mathrm{Sn}$ & 139 & 138 & 52 & 59 & 39 & 36 & $-13^{c}$ \\
\hline $\mathrm{Sb}$ & 109 & 90 & 47 & 39 & 29 & 17 & $-2^{c}$ \\
\hline $\mathrm{Ba}$ & 87 & 45 & 36 & 30 & 22 & 16 & 336 \\
\hline $\mathrm{Fe}$ & 2851 & 2929 & 2072 & 1461 & 855 & 459 & 35848 \\
\hline
\end{tabular}

${ }^{\text {a }}$ Determined by the average of the twelve $480 \mathrm{~s}$ measurements $(\mathrm{mg} / \mathrm{kg})$

${ }^{\mathrm{b}} \mathrm{CrLO}$ and $\mathrm{CrHI}$ relate to the determination of $\mathrm{Cr}$ using the $\mathrm{Cd}-109$ and Fe-55 sources, respectively.

${ }^{\mathrm{c}}$ Negative values for elements with concentrations below the DL are provided for information purposes only; they do not affect MDL calculations.

\subsection{Detection limit versus analysis time}

Table 4 illustrates the dependence of the MDL on analysis time for a representative sample. These results were obtained on a portable EDXRF analyzer using three radioisotope sources and a $\mathrm{HgI}_{2}$ semiconductor detector. Similar results may be obtained for other XRF instruments. Minimum DLs obtained for each analyte by analyzing the sample 12 times at $15,30,60,120,240$, and $480 \mathrm{~s}$ are listed in the table. The DL is defined as three times the standard deviation of the 12 measurements. Generally, the MDL decreases with increased analysis time; however, experimental error may lead to deviations from the expected behavior. Average concentrations reported in the table are calculated from the raw data obtained in the study. Therefore, concentration values below the MDL (including negative values) are reported for information purposes only. DLs are affected by the concentration of the analyte in the sample. Analytes at high concentrations tend to have higher apparent DLs than those at lower concentrations. This highlights the necessity to use a sample with analyte concentrations as close to the MDL as possible. 
Table 5

Certified composition, NIST SRM 2709: SAN JOAQUIN soil

\begin{tabular}{lclc}
\hline Element & Composition (wt.\%) & Element & Composition $(\mu \mathrm{g} / \mathrm{g})$ \\
\hline Aluminum & 7.50 & Antimony & 7.9 \\
Calcium & 1.89 & Arsenic & 17.7 \\
Iron & 3.50 & Barium & 968 \\
Magnesium & 1.51 & Cadmium & 0.38 \\
Phosphorus & 0.062 & Chromium & 130 \\
Potassium & 2.03 & Cobalt & 13.4 \\
Silicon & 29.66 & Copper & 34.6 \\
Sodium & 1.16 & Lead & 18.9 \\
Sulfur & 0.089 & Manganese & 538 \\
Titanium & 0.342 & Mercury & 1.40 \\
& & Nickel & 88 \\
& & Selenium & 1.57 \\
& & Silver & 0.41 \\
& & Strontium & 231 \\
& & Thallium & 0.74 \\
\hline
\end{tabular}

While Table 4 details the DLs for a specific FPXRF analyzer, it is more appropriate to determine the DL for a specific project. Such a DL reflects instrument variability and other sources of error for the set of samples analyzed. Note also that the data in Table 4 was obtained by analyzing the standard 12 times consecutively, thus the DLs are "short-term" data. Actual site data tends to yield DLs that are somewhat larger, reflecting instrument performance over several days or weeks when a soil "standard" is analyzed periodically during field analysis. The standard deviation for the repeat non-consecutive analyses is used to estimate the DL for the analytes of concern.

The choice of an appropriate sample to use for determining actual site DLs requires some trade-offs. The use of a site background sample should match well with site soils in terms of general composition, particle size distribution, and moisture content. Typically, site background soils may be used for the determination of MDLs with good success. However, obtaining a representative background sample is often difficult. Therefore, to standardize the MDL determination, a certified standard soil, NIST 2709, available from the NIST, could be used to determine an estimate for the DL. Table 5 lists the composition of this soil as certified by NIST. Most elements of interest for hazardous waste sites are present at trace levels, making this a useful standard for DL studies. The NIST 2709 sample has been prepared to a finer particle size than is common for most site samples. Therefore, it may provide concentrations by FPXRF analysis that are different than expected due to particle size effects. Several other soil standards, including NIST 2710 and 2711, may be used to determine the accuracy and precision of the analysis at concentrations close to the action levels appropriate for site investigations. 


\subsection{FPXRF analysis of reference materials}

Typically, the elements of interest depend on the environmental application in question. Once the target elements are defined, suitable reference materials are selected for calibrating the FPXRF analyzer (if empirical calibration is required), for determining FPXRF DLs, and for determining accuracy and precision. Standard reference materials (from NIST and other sources) may be used for some applications (e.g. analysis of soils). Site specific calibration standards (analyzed by laboratory methods) may be required when certified materials are not available for the matrix in question. Depending on site action level requirements, FPXRF analysis may not be suitable for some elements due to high DLs, unresolved spectral and matrix interferences, and other instrument limitations.

Tables 6 and 7 show typical FPXRF results for NIST soil standards (numbers 2710 and 2711). The FPXRF analyzer utilized three radioisotope sources, a $\mathrm{HgI}_{2}$ semiconductor detector, and two different FP calibration models. Results were based on the average of 10 measurements with $60 \mathrm{~s}$ acquisition time per source. A number of elements were below the FPXRF MDL. Typically, FPXRF results from the "standard" FP application (Table 6) agreed within $20 \%$ of certified values for elements with concentrations significantly above (more than 10 times) the MDL. Spectral interferences made some elemental analyses difficult; the high Fe content produced high background for $\mathrm{Mn}$ and $\mathrm{Co}$, and $\mathrm{Pb}$ severely interfered with As determination. Additionally, Ba results were approximately $30 \%$ below certified values. The "standard" application had been adjusted to compare to digestion/lab analysis of coarse soils. The "fine particle" application was adjusted to reflect total analyte concentrations in samples such as SRMs. This application (Table 7) was generally in better agreement with certified values for all measurable elements in the SRMs. The data in this table illustrates the usefulness and accuracy of FPXRF for analysis of soil contaminants, and demonstrates the need to adjust FP-based calibrations with certified materials. Furthermore, the data illustrates the need to adjust measurement times to obtain MDLs compatible with hazardous waste site objectives.

\section{Sampling}

Regardless of the instrumentation employed, there are two methods of sample preparation that should be considered when analyzing soil samples by FPXRF: in situ and discrete sampling [7,22-24]. Typically, both methods are employed based on the number of analyses required, site/contaminant history, time allocated to conduct site activities, and proposed sampling design. For direct analysis of contaminated soils (in situ), the XRF instrument may be taken to the sample location and the probe placed directly on the soil surface to measure heavy metal contamination. In situ analysis provides much more flexibility when using a FPXRF unit by allowing rapid collection of data for a large number of sample points, eliminating physical sampling and chain of custody considerations, and yielding real-time data that can be used for rapid decisions in the field.

In the case of discrete sampling (physically removing a sample), significantly more preparation time is required. This limits the number of measurements that can be performed in the time allocated for site activities. The payback for this effort is that analytical accuracy and 
Table 6

Analysis of NIST soil SRMs with a FPXRF analyzer standard application ${ }^{\mathrm{a}}$

\begin{tabular}{|c|c|c|c|c|c|}
\hline \multirow[t]{2}{*}{ Element } & \multirow[t]{2}{*}{$\mathrm{MDL}^{\mathrm{b}}$} & \multicolumn{2}{|c|}{ SRM 2710} & \multicolumn{2}{|c|}{ SRM 2711} \\
\hline & & Certified & $\mathrm{FPXRF}^{\mathrm{c}}$ & Certified & FPXRF $^{c}$ \\
\hline K & - & 21100 & 25600 & 24500 & 28900 \\
\hline $\mathrm{Ca}$ & - & 12500 & 13700 & 28800 & 34900 \\
\hline $\mathrm{Ti}$ & - & 2830 & 2800 & 3060 & 2920 \\
\hline $\mathrm{CrLO}^{\mathrm{d}}$ & 295 & $(39)^{\mathrm{e}}$ & ND & $(47)^{\mathrm{e}}$ & ND \\
\hline $\mathrm{CrHI}^{\mathrm{d}}$ & 743 & $(39)^{\mathrm{e}}$ & ND & $(47)^{\mathrm{e}}$ & ND \\
\hline $\mathrm{Mn}^{\mathrm{f}}$ & 1010 & 10100 & 12800 & 638 & ND \\
\hline $\mathrm{Fe}$ & - & 33800 & 32300 & 28900 & 25700 \\
\hline $\mathrm{Co}^{\mathrm{f}}$ & 1160 & $(10)^{\mathrm{e}}$ & ND & $(10)^{e}$ & ND \\
\hline $\mathrm{Ni}$ & 350 & 14 & ND & 21 & ND \\
\hline $\mathrm{Cu}$ & 137 & 2950 & 2740 & 114 & ND \\
\hline $\mathrm{Zn}$ & 204 & 6952 & 6080 & 350 & 293 \\
\hline As & 134 & 626 & $231^{\mathrm{g}}$ & 105 & $\mathrm{ND}^{\mathrm{g}}$ \\
\hline $\mathrm{Se}$ & 59 & NA & ND & 1.5 & ND \\
\hline $\mathrm{Sr}$ & 72 & $(240)^{\mathrm{e}}$ & 387 & 245 & 294 \\
\hline $\mathrm{Zr}$ & 44 & NA & 153 & $(230)^{\mathrm{e}}$ & 320 \\
\hline Mo & 13 & $(19)^{\mathrm{e}}$ & 26 & $(1.6)^{\mathrm{e}}$ & ND \\
\hline $\mathrm{Hg}$ & 150 & 33 & ND & $(6.3)^{\mathrm{e}}$ & ND \\
\hline $\mathrm{Pb}$ & 66 & 5532 & 4920 & 1162 & 1050 \\
\hline $\mathrm{Rb}$ & 79 & $(120)^{\mathrm{e}}$ & 154 & $(110)^{\mathrm{e}}$ & 122 \\
\hline $\mathrm{Cd}$ & 110 & 22 & ND & 42 & ND \\
\hline Sn & 67 & NA & ND & NA & ND \\
\hline $\mathrm{Sb}$ & 52 & 38 & ND & 19 & ND \\
\hline $\mathrm{Ba}$ & 58 & 707 & 425 & 726 & 476 \\
\hline $\mathrm{Ag}$ & 85 & 35 & ND & 4.6 & ND \\
\hline
\end{tabular}

${ }^{a}$ All concentrations in mg/kg; three sources: Cd-109, Fe-55, Am-241; $60 \mathrm{~s}$ acquisition time per source; fundamental parameters calibration ("standard" soils); MDL: method detection limit; ND: not detected (less than the MDL); NA: not available.

${ }^{\mathrm{b}}$ MDL determined using NIST SRM 2709.

${ }^{\mathrm{c}}$ FPXRF results are average of 10 analyses.

${ }^{\mathrm{d}}$ CrLO: Cr results with Fe-55 source; CrHI: Cr results with Cd-109 source.

${ }^{\mathrm{e}}$ Parentheses indicate that the value is not certified but provided for information purposes only.

${ }^{\mathrm{f}}$ High MDLs for Mn and Co due to high background contribution from Fe X-ray line.

${ }^{\mathrm{g}} \mathrm{Pb}$ interferes with As measurement $(\mathrm{Pb}$ concentration is 9-11 times that of $\mathrm{As})$.

precision are generally improved for prepared samples compared to in situ measurements. Site data quality objectives (DQO) determine which sample preparation method is most appropriate $[25,26]$. Typical procedures for in situ and discrete sample measurements are discussed elsewhere [27].

\subsection{Representative samples}

To accurately characterize site conditions, samples collected must be representative of the site or area under investigation [28]. Representative soil sampling ensures that a sample or group of samples accurately reflects the concentration of the contaminant(s) of concern at a 
Table 7

Analysis of NIST soil SRMs with a FPXRF analyzer fine particle application ${ }^{\mathrm{a}}$

\begin{tabular}{|c|c|c|c|c|c|}
\hline \multirow[t]{2}{*}{ Element } & \multirow[t]{2}{*}{$\mathrm{MDL}^{\mathrm{b}}$} & \multicolumn{2}{|c|}{ SRM 2710} & \multicolumn{2}{|c|}{ SRM 2711} \\
\hline & & Certified & $\mathrm{FPXRF}^{\mathrm{c}}$ & Certified & FPXRF $^{c}$ \\
\hline K & - & 21100 & 21400 & 24500 & 24400 \\
\hline $\mathrm{Ca}$ & - & 12500 & 11700 & 28800 & 30000 \\
\hline $\mathrm{Ti}$ & - & 2830 & 2800 & 3060 & 2970 \\
\hline $\mathrm{CrLO}^{\mathrm{d}}$ & 266 & $(39)^{\mathrm{e}}$ & ND & $(47)^{\mathrm{e}}$ & ND \\
\hline $\mathrm{CrHI}^{\mathrm{d}}$ & 993 & $(39)^{\mathrm{e}}$ & ND & $(47)^{\mathrm{e}}$ & ND \\
\hline $\mathrm{Mn}^{\mathrm{f}}$ & 787 & 10100 & 9490 & 638 & 890 \\
\hline $\mathrm{Fe}$ & - & 33800 & 33400 & 28900 & 27400 \\
\hline $\mathrm{Co}^{\mathrm{f}}$ & 747 & $(10)^{\mathrm{e}}$ & ND & $(10)^{e}$ & ND \\
\hline $\mathrm{Ni}$ & 233 & 14 & ND & 21 & ND \\
\hline $\mathrm{Cu}$ & 113 & 2950 & 2700 & 114 & ND \\
\hline $\mathrm{Zn}$ & 126 & 6952 & 6530 & 350 & 391 \\
\hline As & 79 & 626 & $463^{g}$ & 105 & $\mathrm{ND}^{\mathrm{g}}$ \\
\hline $\mathrm{Se}$ & 60 & NA & ND & 1.5 & ND \\
\hline $\mathrm{Sr}$ & 37 & $(240)^{\mathrm{e}}$ & 401 & 245 & 298 \\
\hline $\mathrm{Zr}$ & 59 & NA & 161 & $(230)^{\mathrm{e}}$ & 320 \\
\hline Mo & 12 & $(19)^{\mathrm{e}}$ & 18 & $(1.6)^{\mathrm{e}}$ & ND \\
\hline $\mathrm{Hg}$ & 131 & 33 & ND & $(6.3)^{\mathrm{e}}$ & ND \\
\hline $\mathrm{Pb}$ & 96 & 5532 & 5680 & 1162 & 1230 \\
\hline $\mathrm{Rb}$ & 43 & $(120)^{\mathrm{e}}$ & 158 & $(110)^{\mathrm{e}}$ & 129 \\
\hline $\mathrm{Cd}$ & 145 & 22 & ND & 42 & ND \\
\hline Sn & 81 & NA & ND & NA & ND \\
\hline $\mathrm{Sb}$ & 65 & 38 & ND & 19 & ND \\
\hline $\mathrm{Ba}$ & 111 & 707 & 727 & 726 & 778 \\
\hline $\mathrm{Ag}$ & 83 & 35 & 104 & 4.6 & ND \\
\hline
\end{tabular}

${ }^{a}$ All concentrations in mg/kg; three sources: Cd-109, Fe-55, Am-241; $60 \mathrm{~s}$ acquisition time per source; fundamental parameters calibration ("fine particle" soils); MDL: method detection limit; ND: not detected (less than the MDL); NA: not available.

${ }^{\mathrm{b}}$ MDL determined using NIST SRM 2709.

${ }^{\mathrm{c}}$ FPXRF results are average of 10 analyses.

${ }^{\mathrm{d}}$ CrLO: Cr results with Fe-55 source; CrHI: Cr results with Cd-109 source.

${ }^{\mathrm{e}}$ Parentheses indicate that the value is not certified but provided for information purposes only.

${ }^{\mathrm{f}}$ High MDLs for Mn and Co due to high background contribution from Fe X-ray line.

${ }^{\mathrm{g}} \mathrm{Pb}$ interferes with As measurement ( $\mathrm{Pb}$ concentration is 9-11 times that of $\left.\mathrm{As}\right)$.

given time and location. Analytical results from representative samples reflect the variation in contaminant presence and concentration range throughout a site. Parameters affecting representative sampling include: (1) geologic variability, (2) contaminant concentration variability, (3) collection and preparation variability, and (4) analytical variability.

\subsection{Sample moisture}

If measurement of soils or sediments is intended, the sample moisture content affects the accuracy of the analysis. Sample dilution tends to decrease the apparent concentration 
as the moisture level increases. This effect is most severe for analytes with low energy $\mathrm{X}$-ray lines (less than $5 \mathrm{keV}$ ), and may be negligible for elements with higher energy X-ray lines (for example, $\mathrm{Pb}$ ). To some extent, the dilution effect may be counteracted by the reduced matrix absorption for the analyte $\mathrm{X}$-ray lines when water replaces the higher atomic number (and, therefore, more absorbing) soil/sediment matrix. The direction and magnitude of the bias introduced by moisture is, therefore, dependent on the analyte X-ray line energy and the composition of the sample. The overall error may be minor when the moisture content is small (5-20\%), but it may be a major source of error when the soil is saturated with water [29]. Soil/sediment samples should be dried when moisture content is greater than $20 \%$.

\subsection{Sample placement and probe geometry}

Sample placement is a potential source of error, since the X-ray signal decreases as the distance from the radioactive source increases. This error can be minimized by maintaining the same source to sample distance for all measurements. When performing in situ measurements, the probe surface should be parallel to the sample surface, which must be flat. The goal is to place a flat compacted soil surface against the probe's sample presentation plane, achieving maximum surface to surface contact between the sample and probe. Variations in measurement geometry may cause X-ray signal attenuation and, consequently, erroneous results.

\subsection{Physical matrix effects}

Physical matrix effects (due to sample morphology) are the result of variations in the physical character of the sample, and include parameters such as particle size, uniformity, heterogeneity, and surface condition [7]. These parameters vary depending on the conditions present at each site, and must be monitored closely to determine if they bias the FPXRF results. When prepared soil/sediment samples are stored in XRF cups, settling effects may also bias results. If the cups are stored window film side down, the finer particles tend to settle against the window, and XRF results may be biased high for the elements in those particles. Conversely, XRF results may be biased high for elements in larger particles if the cups are stored window film side up. To minimize these effects, the cups should be shaken and tapped on a flat surface to pack the sample against the window film prior to XRF analysis.

\subsection{Depth of X-ray penetration}

$\mathrm{XRF}$ analysis of soils is a surface analytical technique regardless of the $\mathrm{X}$-ray source and instrumentation involved. The maximum depth of $\mathrm{X}$-ray penetration using sealed radioisotope sources is approximately $2 \mathrm{~mm}$ in a soil matrix, therefore, as little as $5 \mathrm{~mm}$ of clean material can mask contaminated soil. For FPXRF analysis, this means that more than $5 \mathrm{~mm}$ of soil is considered to be infinitely thick (the depth at which $99 \%$ of the analyte X-rays have been generated). In situ soil measurements are always infinitely thick. However, when 
analyzing soil in sample cups, the material must nearly fill the XRF sample cup (at least three-quarters full) to ensure that the sample is effectively infinitely thick.

\subsection{Effects of sample containers}

The composition and thickness of materials located between the sample and probe window affects absorption of light element X-ray lines, which in turn affects results from FP-based instruments [30]. Measurements made with XRF sample cups should employ 0.2-mil Mylar or polypropylene X-ray film, which has negligible attenuation effects for most contaminant element $\mathrm{X}$-ray lines and is of uniform thickness and composition. If plastic bags are used to collect and measure soil/sediment samples, the XRF analyzer must have been calibrated using the same thickness plastic to minimize these effects. In the case of instruments using FP-based calibrations, only a thin layer of 0.2-mil Mylar or polypropylene should be used to protect the probe from cross-contamination.

\section{QA/QC and data interpretation}

\subsection{Quality assurance objectives and XRF}

For each data collection activity established at a hazardous waste site, a quality assurance (QA) objective must be specified that corresponds to the ultimate data use objective. The US EPA has defined three objectives (QA1, QA2, and QA3) for assessing and substantiating data collection [25]. The characteristics of each QA objective should be evaluated to determine which one or combination fits the data use objective(s) established for the site.

QA1 is a screening objective used to afford a quick, preliminary assessment of site contamination, and is suitable for data collection activities that involve rapid, non-rigorous methods of analysis and QA. QA2 is a verification objective used to verify screened data (field or laboratory) or data generated by any method that satisfies the QA2 requirements. A minimum of $10 \%$ verification of results is required. This objective is suitable for data collection activities that require qualitative and/or quantitative verification of all or a select portion (10\% or more) of the data. QA2 is intended to give a level of confidence for a select portion of the preliminary data. QA3 is a definitive objective used to assess the accuracy of the concentration level as well as the identity of the analyte of interest. It is suitable for data collection activities that require a high degree of both qualitative and quantitative accuracy. Rigorous analytical methods and quality assurance are conducted to give a high level of confidence in the quantitative results for "critical samples".

XRF measurements can fit into QA1 or QA2 objectives. If the site objectives are characterization or determination of the relative magnitude of contamination, XRF measurements fit the QA1 objective. If verification of the extent of contamination or verification of cleanup effectiveness is required, QA2 objectives may be attained by submitting a minimum of $10 \%$ of the samples for confirmation analysis by a US EPA-approved laboratory method (such as atomic absorption (AA) or inductively coupled plasma (ICP) analysis). XRF is rarely used in conjunction with the QA3 objective, due to the increase in time and laboratory costs associated with this objective. 


\section{2. $Q A / Q C$ considerations}

Depending on the particular XRF instrument employed, various types of QC samples are required to ensure data integrity. In some instances, the rate of QC samples is dependent on the data quality objective established for the site. In all cases, measurements of field QC samples or calibration check measurements should be recorded as a part of the permanent site record.

\subsubsection{Precision}

Precision is determined by repeat non-consecutive measurements of a sample at or near the action level or level of concern established for the site [7,31]. This sample should be analyzed before any site samples are measured, after every tenth sample or sampling location, and after site activities are completed. The sample should be measured a minimum of eight times, the individual results reported, and the average, standard deviation, and percent relative standard deviation (\% R.S.D.) calculated. A critical feature of this QC sample is that it be at or near the site action level to be most beneficial. The precision objective for FPXRF measurements should be $\pm 20 \%$ R.S.D. [7]. Determining precision near the action level can be extremely important if the XRF results are to be used in an enforcement action. A site-specific sample that has been analyzed by approved laboratory methods can be used for precision measurements. Alternatively, a standard reference material (SRM) may be employed.

\subsubsection{Accuracy}

Instrument performance should be monitored while field measurements are made [7,22,32]. Instrument checks (energy calibration, detector resolution, etc.) can be used to monitor instrument stability. Characterized samples at mid-calibration range or several times the action level should be measured to determine calibration performance for the site target elements. For site-specific calibrations, several sets of check samples may be required due to site matrix differences. For FP quantitation models, check samples may be either well characterized site samples or soil SRMs. Instrument stability checks should be done at the beginning of the day prior to site measurements. Calibration performance check samples should be analyzed at the beginning of the day and after every 10 sample locations.

\subsubsection{Comparability}

To determine field data quality, XRF results are generally compared to laboratory data obtained using a sample digestion procedure. XRF data that correlate directly to laboratory data are considered comparable to the digestion/analysis methods used. For site-specific XRF calibrations, SSCS that have been analyzed by a laboratory method are required to calibrate the instrument. Once properly calibrated, the XRF instrument produces results that would be similar to those obtained by the laboratory method. Significant variance has been reported for extraction recovery of different metals in different soil matrices when several laboratories used identical EPA-approved digestion methods [33]. Therefore, comparison of XRF data to laboratory data may be highly dependent upon the sample matrix, the digestion/extraction methodology, and the laboratory analyzing the samples. 
Another issue of comparability arises when multiple XRF units are on site at the same time [32]. In this case, check samples from the same sample source/lot must be measured on all XRF units to establish comparability of results from the different analyzers. These may be well characterized site samples or SRMs that contain the target elements at concentrations near their respective action levels.

\subsubsection{Replicate samples}

Two types of replicate sample measurements should be considered when performing FPXRF analysis. For extent of contamination (EOC) studies or site assessments, field duplicates are recommended at a minimum rate of 5\%. Duplicate samples should be prepared independently of other samples using the same sample preparation procedure. Field duplicates provide a check on variability (heterogeneity) of the sample matrix, consistency of sample preparation, and precision of the analysis, and should be within $\pm 20 \%$ [7]. If FPXRF analysis is utilized as part of a cleanup verification objective, then eight replicate samples from one location may be employed for analytical error determination [25]. This error determination procedure is optional, but when employed generates information about the confidence level that can be associated with the sampling method or sample preparation method.

\subsubsection{Confirmation samples}

Accuracy, relative to a specific digestion method and elemental analysis procedure, is best determined by using site-specific, low-, mid-, and high-level samples that have been analyzed by laboratory methods. For a total accuracy check, confirmation samples should be collected throughout the entire sampling effort (minimum 10\% with a number of samples at or near the critical level). The results of laboratory analysis (dependent) and XRF analysis (independent) are evaluated with regression analysis. The coefficient of determination $\left(r^{2}\right)$, for the element of interest, should be 0.7 or greater to satisfy QA2 DQO [7].

Based on the QA objectives established for the site, confirmation samples may or may not be utilized to achieve site goals. If QA1 objectives have been established for the site, there is no requirement to collect and analyze confirmation samples. However, confirmation samples may still be collected to verify that the XRF instrument is producing reliable results. The percentage of confirmation samples required is determined on a site-specific basis. If QA2 objectives have been established for the site, then confirmation samples are required [7]. Ideally, the sample that was analyzed by XRF should be the same sample that is submitted for laboratory analysis. For in situ analyses, a single sample should be collected for both XRF measurement (in an XRF sample cup) and confirmation analysis. If sample splits are employed to prepare confirmation samples, care must be exercised to ensure that the XRF and laboratory instruments "see" the same sample matrix. The entire sample lot must be carefully prepared and blended prior to the split, and all samples must be prepared in the same way (splits as well as ordinary samples).

\subsubsection{Standard reference materials}

Three soil SRMs $(2709,2710,2711)$ are available from the National Institute of Standards and Technology [18]. Each was developed and certified for more than 25 elements. 
Additionally, two sediment SRMs (1646 and 2704) are available. The National Research Council Canada, Institute for Environmental Chemistry [34] provides three marine sediment reference materials for trace elements (MESS-1, BCSS-1, PACS-1) that could be useful as PE and DL standards. Purified acid-washed sand is available from several commercial vendors, and may be used to provide a zero concentration (clean matrix) sample.

\subsubsection{Field reporting of XRF data}

Generally, XRF instruments calculate and may report results to a higher degree of significance than is warranted by their measurement precision and calibration accuracy. FPXRF analyzers are typically accurate to two or three significant figures. For final reports, and comparison to laboratory analysis of calibration and confirmation samples, FPXRF results should typically be rounded to two significant figures.

\subsubsection{Method detection limits}

Measurement times should be adjusted so that XRF DLs are well below site action levels whenever possible. For empirical calibrations, a site-specific background sample that has low concentrations for the elements of interest should be used to determine the XRF MDLs for the site. For FP-based calibrations, SRMs may be utilized to determine site MDLs. The MDL sample should be measured at the beginning of site activities, after every tenth sample or sampling location, and at the end of site activity.

\subsection{Interpretation of data}

\subsubsection{Evaluating confirmation sample data}

When evaluating XRF results, graphical and statistical analyses should be used to ensure that the data accurately characterizes the site $[32,35,36]$. Verification or confirmatory samples taken from the data set are used in this evaluation process. There are two possible options: (1) random selection of the samples, and (2) subjective selection of low-, mid-, and high-concentration samples to ensure a wide range of values. If an appropriate number of confirmatory samples are taken, the random selection process should be representative of the entire range of concentrations being sampled, making subjective selection unnecessary. An initial set of random samples should be chosen for statistical analyses, and if necessary, followed by subjective selection of additional samples to provide a wide range of concentration values. A number of confirmation samples should be from site locations with contaminant concentrations at or near the action level.

\subsubsection{Values below the detection limit}

Values below the XRF DL pose a problem with most statistical analyses, and they should be used with caution due to the bias that they can introduce. Several methods may be utilized to handle these values [35]: (1) all data points should be used unless otherwise proven that they are anomalies or errors; (2) if a large number of XRF values are below the DL, laboratory results should be used to verify them; (3) if a low percentage of these values occurs, statistical analyses should be run with and without such values to determine their influence, and (4) depending on the instrumentation, either zero, half the DL, or the 
DL may be substituted for values below the XRF DL. In general, statistical analyses should not be performed with fewer than eight data points.

\subsubsection{Statistical analysis}

Several statistical analysis methods may be used to evaluate and compare XRF and confirmatory data $[27,32]$. The minimum statistical treatment that should be done for confirmation samples is regression analysis to evaluate if a linear relationship exists between the independent variable (XRF data) and the dependent variable (confirmatory laboratory data). Regression results should be plotted as a visual aid to determine the significance of the linear model and to identify potential outliers.

\subsubsection{Correlation analysis}

Correlation analysis is related to regression analysis. It determines the degree of linearity between two sets of data, and may be utilized prior to linear regression analysis. A correlation coefficient $(R)$ is generated in the analysis, and ranges in value from -1.0 (a perfect negative linear correlation) to 1.0 (a perfect positive linear relationship). A zero value indicates no linear relationship exists. If a strong linear relationship exists, linear regression analysis should be used to evaluate the data sets. If non-linear relationship exists, a non-linear regression analysis may be considered.

\subsubsection{Regression analysis}

Regression analysis [36] is used to fit a model between an independent variable and a dependent variable to determine if a linear relationship exists between the variables and if that relationship is significant. Regression analysis yields the coefficient of determination $\left(r^{2}\right)$, which defines the proportional amount of variability explained by the regression model. The $r^{2}$ value ranges from 0.0 , which means no variability to 1.0, which indicates that $100 \%$ of the variability is explained by the model. If the $r^{2}$ value is high $(>0.7)$, the regression model is significant.

Graphical presentation of the regression model (Fig. 3) gives an intuitive feel for the data, and a better understanding of the model. If there is a wide range of values, the data should be plotted on different scales to observe the impact that high or low values may have on the model. If several different models are used, they should be plotted together for comparison purposes. The model that is most meaningful, i.e. the one that omits outliers and retains data bracketing action level concentrations, should be used for final evaluation of the XRF data.

The residuals of the regression model should be examined for outliers (Fig. 4). The residuals are the differences between the predicted dependent values and the actual dependent values. A plot of residuals versus dependent values should be a random scattering of points about the zero residual line. Anomalies or outliers are usually apparent. If any outliers are present, the regression analysis should be performed without these values to determine their impact upon the model. If the sample size for regression is small (less than eight observations), removal of data points should be avoided because removal greatly increases the error associated with the regression analysis.

Fig. 5 illustrates the effect that significant outliers can have on a regression model. Several samples ( 8 of 210 total) had laboratory results significantly higher than FPXRF analysis. 


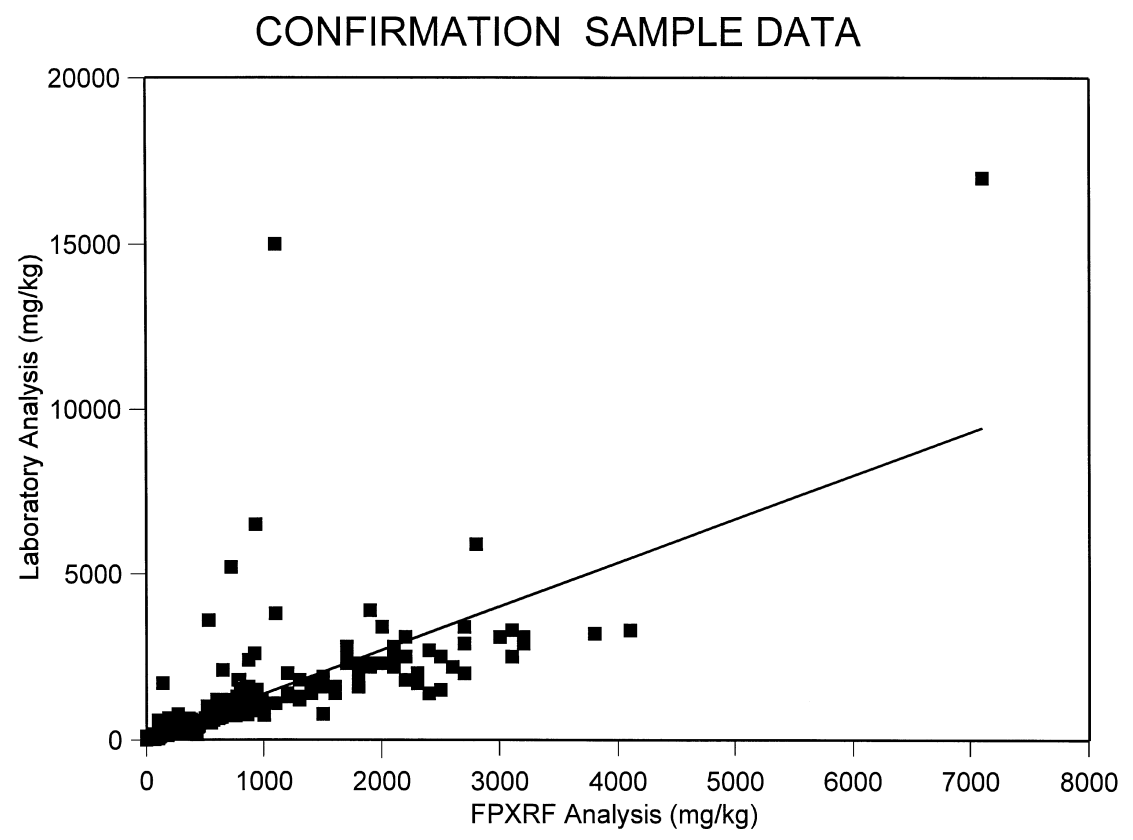

Fig. 3. Graphical representation of regression analysis results.

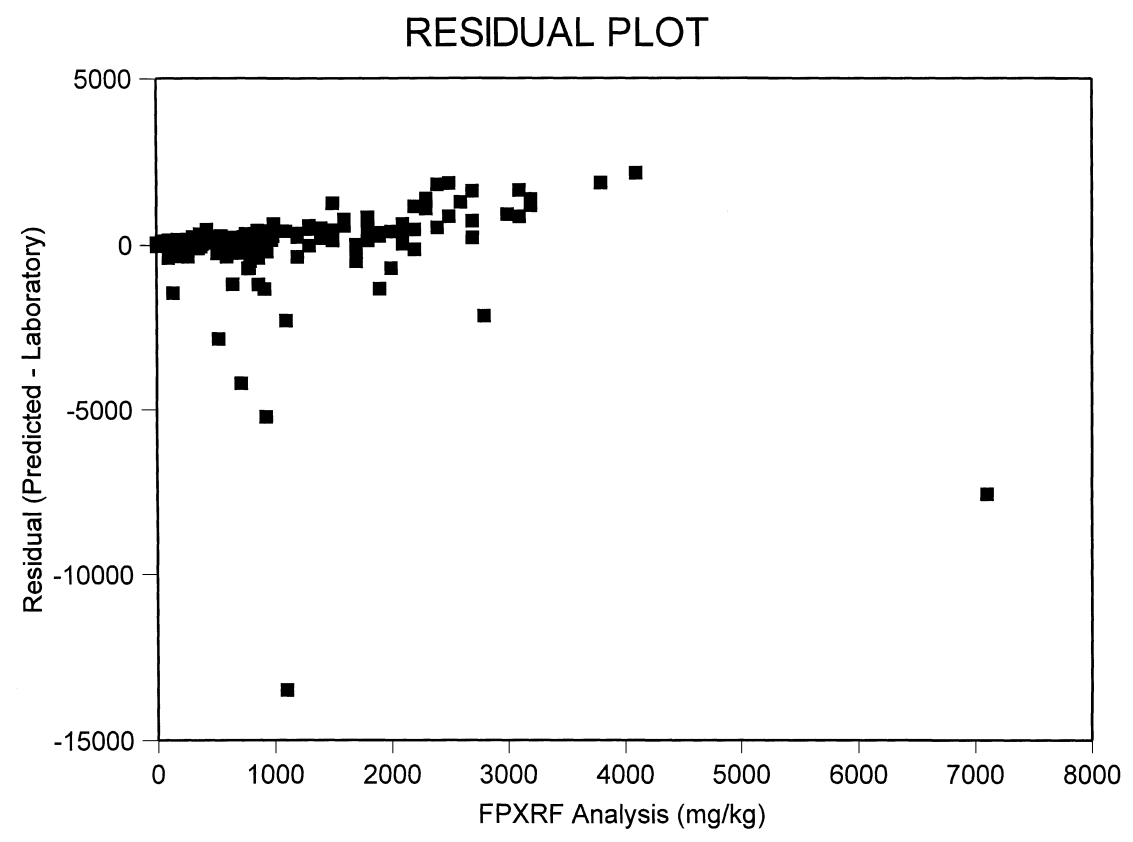

Fig. 4. Regression analysis: residual plot. 


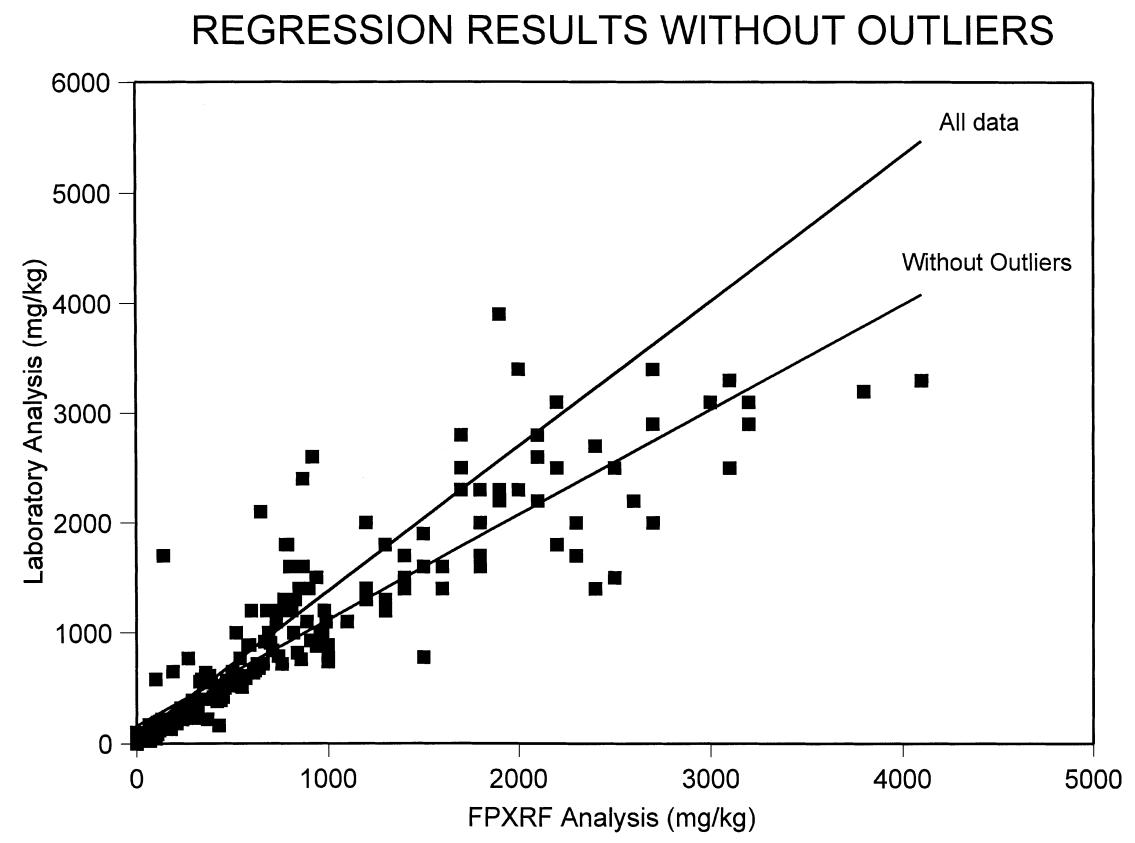

Fig. 5. Effect of outliers on regression analysis models.

This produced an artificially high slope (approximately 1.3) for the regression, and QA2 data objectives $\left(r^{2}>0.7\right)$ were not met. This may be indicative of the "nugget" effect, where the laboratory sample (typically only $1 \mathrm{~g}$ ) may have contained a small "nugget" of analyte resulting in a high laboratory result for the sample. Removal of the potential outliers yielded a regression with slope of 0.958 , greatly improved $r^{2}$ value $(0.836)$, and better agreement with data bracketing the action level. This was the most meaningful regression analysis for evaluating FPXRF performance for this data set.

\section{Advantages and disadvantages}

The environmental community has accepted FPXRF methodology as a viable cost- and time-effective analytical approach for analyzing a variety of hazardous materials [31,37-39]. FPXRF analysis offers many advantages and few disadvantages compared to conventional contract laboratory program (CLP) methods that have historically been employed for analysis of environmental samples.

FPXRF analyzers are generally less sensitive (have higher DLs) than laboratory methods, however, results are sufficient to meet site action level requirements in most cases. FPXRF results are typically surface measurements only; therefore, sampling location, preparation, and homogenization are important for in situ measurements. Additionally, FPXRF analyzers are subject to physical matrix effects due to variations in the physical character of the 
sample. Physical matrix effects can also deteriorate the quality of laboratory results. Most FPXRF analyzers employ radioisotope sources for sample excitation; these sources have finite useful lifetimes (defined by their half-life), and must be replaced at regular intervals (typically, every 2-4 years) by the instrument vendor. Furthermore, use of radioisotope source based instruments is governed by the US Nuclear Regulatory Commission and various state agencies.

The source/detector combination may dictate the choice of the FPXRF analyzer best suited for a given application. The source(s) must be able to efficiently excite the elements of interest, and the detector must be able to resolve them. FPXRF instruments employing solid-state semiconductor detectors generally have better DLs for most elements than proportional counter-based systems. Proportional counter detectors typically have significantly poorer resolution than semiconductor devices; therefore, they are less able to resolve X-ray spectral overlaps. This means that calibration of certain element combinations may be impossible solely due to detector limitations.

On-site availability of FPXRF analysis maximizes analytical coverage while minimizing costs, providing site managers with the near real-time data necessary to guide critical field decisions in extent of contamination, removal, and remedial actions. In situ measurement capabilities minimize time spent on physical sample collection and preparation, and eliminate shipping and sample custody considerations. Rapid field screening capabilities (QA1 data) allow analysis of a large number of samples in a short period of time, providing costand time-effective delineation of contaminant distributions. QA2 data objectives are readily achievable with $10 \%$ laboratory confirmation of field data. Denser sampling grids may be employed, which reduces the possibility of missing "hot spots" and increases the reliability of decisions based on spatial models delineating the extent of contamination. Multiple sample types (e.g. soils, thin films, paint) may be analyzed with the same FPXRF analyzer by utilizing different application models stored in memory. Furthermore, most FPXRF analyzers provide field storage of results and X-ray spectra as well as downloading capabilities to facilitate reporting of results and QA/QC verification of the field data. Finally, minimal operator training is required, and reliable results are readily obtained by utilizing well-defined QA/QC procedures. FP-based FPXRF analyzers provide additional capabilities for qualitative and quantitative analysis of samples without the need for site-specific calibration standards. This is a very useful feature and can be extremely important for emergency response situations where reaction time is critical and such standards are not available. It is also useful for assessment and removal activities where the sample matrix varies widely over the site.

The US Environmental Protection Agency's Environmental Response Team (US EPA/ ERT) leads the efforts to utilize on-site analytical support to assist on-scene coordinators (OSCs) and remedial program managers (RPMs) in conducting extent of contamination studies, as well as removal and remedial operations in an efficient manner. On-site analytical support enables site managers to take quick and responsive action; it also saves enormous amounts of time and cost due to the rapid turnaround of analysis results. The US EPA/ERT has successfully utilized FPXRF on-site support to characterize metallic contamination in soils/sediment and other media at many hazardous waste sites [27,31]. Advances in hardware, software, and sample handling procedures have enabled the US EPA/ERT to expand the use of FPXRF technologies and still meet strict data quality requirements. To meet these requirements, the US EPA/ERT developed written standard operating procedures 
(SOPs) that optimize the accuracy and precision of FPXRF data when compared to standard laboratory extraction procedures, followed by AA or ICP analysis [9,40]. The US EPA Office of Solid Waste and Emergency Response has also issued a method for FPXRF analysis of soil and sediment [41]. Today, FPXRF is widely accepted as the analytical method of choice when addressing most metals contaminated hazardous waste sites.

\section{Other FPXRF applications}

\subsection{Testing lead-based paint}

Portable XRF analyzers have been successfully utilized since the 1970s for testing lead-based paint during exposure and abatement studies. These analyzers have typically been pre-calibrated by the manufacturer using certified lead-in-paint standards. A number of source/detector configurations are employed for these analyzers. Typically, they measure $\mathrm{K}$-series lead radiation in the $70-88 \mathrm{keV}$ range. Some analyzers, however, employ L-series measurements in the 10-15 keV range or allow analysis of both the K- and L-series lead lines. The sources commonly used for K-series excitation are cobalt-57 (Co-57), which emits radiation at approximately $120 \mathrm{keV}$, and cadmium-109 (Cd-109), which emits radiation just above the lead K-absorption edge $(88 \mathrm{keV})$. The $\mathrm{Cd}-109$ source also emits radiation in the $22-25 \mathrm{keV}$ region that can efficiently excite lead L-series X-ray lines. A curium-244 $(\mathrm{Cm}-244)$ source may also be used to excite lead L-lines [42]. The relatively high energy emitted by the Co- 57 source poses some radiation hazards to operators who must complete a radiation safety course approved by the US Nuclear Regulatory Commission prior to using Co-57 based instruments. Several different types of X-ray detection systems are used in portable XRF lead-based paint analyzers. Gas proportional counters or solid-state detectors are most commonly used; solid-state detectors typically have better spectral resolution capabilities than proportional counters. Analyzers may also differ in the way that they process spectral data; direct readers only process X-ray data from lead, while spectrum analyzers process the entire spectrum including scattered source $\mathrm{X}$-rays.

XRF measurement of lead-based paint is susceptible to variable scattering of the source $\mathrm{X}$-rays from the substrate material beneath the paint layers. Portable lead-in-paint XRF analyzers typically provide corrections for substrate scattering. The effectiveness of these corrections depends on the substrate material, the lead X-ray line measured, the source/ detector combination, and how the analyzer processes spectral data. Generally, the higher energy sources used for $\mathrm{K}$-shell excitation penetrate deeper into the substrate and require greater substrate corrections. This limits the achievable DL to the order of $1 \mathrm{mg} / \mathrm{cm}^{2}$. DLs on the order of $0.1-0.2 \mathrm{mg} / \mathrm{cm}^{2}$ are possible with L-shell excitation using Cd-109 sources due to minimization of substrate scattering, since the $\mathrm{Cd}-109$ source $\mathrm{X}$-rays do not penetrate as deeply into the substrate. Furthermore, depending on the X-ray line measured (K-shell or L-shell), the analysis may also be affected by the paint matrix and the number of overlying layers.

Increased interest in the potential impact on health from environmental lead has resulted in an increase in the number of Federal, State, and local Government programs committed to sampling and analysis of lead in paint, soil, and household dust [40,42-45]. Laboratory 
methods, portable XRF analyzers, and other field testing technologies have been evaluated with respect to their suitability for analysis of lead-based paint [46,47]. Field tests were performed to establish accuracy, bias, precision, and susceptibility to substrate effects using representative building materials as substrates. Results of these evaluations indicated that portable XRF technology was the preferred method for field testing lead-based paints. Chemical test kits were generally not successful in discriminating accurately between lead-based and non-lead paints and, therefore, could not provide information on the extent of lead-based paint in a home. The primary XRF conclusion of the study was that testing using K-shell XRF instruments was a viable way to test for lead-based paint, provided that laboratory analysis was used to confirm inconclusive XRF results and substrate correction was applied to reduce biases.

\subsection{Additional applications}

Portable XRF techniques have been successfully applied to other environmental applications including: field screening air monitoring filters for metals [15], airborne particulates in battery manufacture [48], lead in drinking water [49], underwater and on-board sediment analysis [50,51], uranium in soil and sediment [52], lead in workplace air [53], lead contamination of carpeted surfaces [54], in situ analysis of lead on high volume filters [55], and uranium and technicium in concrete and metals [56].

\section{Conclusions}

FPXRF methodology provides a viable, cost- and time-effective approach for on-site analysis of a variety of environmental samples. FPXRF results provide both qualitative and quantitative information about site contamination. The US EPA/ERT has successfully utilized FPXRF instruments for on-site analysis of metals contamination in soils and sediments to guide evaluation/removal programs at numerous hazardous waste sites. Portable $\mathrm{XRF}$ technology is the preferred method for field testing lead-based paints during exposure studies and abatement actions. FPXRF further provides rapid non-destructive on-site capabilities for analyzing filters, wipes, and other thin sample applications.

\section{Acknowledgements}

The authors wish to thank Jay Patel and Bill Cole of Lockheed Martin/REAC and George Prince of the US EPA/ERT for their technical and editorial support during this project. Mention of trade names or commercial products does not constitute endorsement or recommendation for their use.

\section{References}

[1] E.P. Bertin, Principles and Practice of X-Ray Spectrometric Analysis, 2nd Edition, Plenum Press, New York, 1975. 
[2] R. Jenkins, An Introduction to X-Ray Spectrometry, Heyden, London, 1976.

[3] R. Jenkins, R.W. Gould, D. Gedcke, Quantitative X-Ray Spectrometry, Marcel Dekker, New York, 1981.

[4] J.V. Gilfrich, L.S. Birks, Portable Vacuum X-Ray Spectrometer, Instrument for On-Site Analysis of Airborne Particulate Sulfur and Other Elements, Naval Research Laboratory, EPA-600/7-78-103, NIST PB-285678, June 1978.

[5] G.A. Raab, D. Cardenas, S.J. Simon, L.A. Eccles, Evaluation of a Prototype Field Portable X-Ray Fluorescence System for Hazardous Waste Screening, EPA/600/4-87/021, NIST PB87-227633, August 1987.

[6] R.A. Jenkins, F.F. Dyer, R.L. Moody, C.K. Bayne, C.V. Thompson, Experimental Evaluation of Selected Field Portable Instrumentation for the Quantitative Determination of Contaminant Levels in Soil and Water at Rocky Mountain Arsenal, Final Report, Oak Ridge National Laboratory, ORNL/M-11385, October 1989.

[7] US EPA/ERT, Field Portable X-Ray Fluorescence, Quality Assurance Technical Information Bulletin, 1 (no. 4), May 1991.

[8] A.R. Harding, Fundamental Parameter Method EDXRF Analysis of Contaminated Soils, Spectrace Instruments, Fort Collins, $\mathrm{CO}$.

[9] US EPA/ERT, SOP 1707, X-MET 880 Field Portable X-Ray Fluorescence Operating Procedures, December 1994.

[10] HAZ-MET 880 Operator's Manual, Outokumpu Electronics Inc., 18 September 1991.

[11] D.J. Kalnicky, A combined fundamental alphas/curve fitting algorithm for routine XRF sample analysis, Adv. X-Ray Anal. 29 (1986) 451-460.

[12] D.J. Kalnicky, EDXRF analysis of thin films and coatings using a hybrid alphas approach, Adv. X-Ray Anal. 29 (1986) 403-412.

[13] D.J. Kalnicky, M. Bernick, L. Kaelin, R. Singhvi, G. Prince, Optimization of fundamental parameters methods for analysis of hazardous materials with field-portable XRF analyzers, in: Proceedings of an International Symposium on Field Screening Methods for Hazardous Wastes and Toxic Chemicals, VIP-47, Vol. 2, Air and Waste Management Association, Pittsburgh, PA, 1995, pp. 1103-1105.

[14] T.G. Duzbay, X-ray Fluorescence Analysis of Environmental Samples, Ann Arbor Science, Ann Arbor, MI, 1977.

[15] M.B. Bernick, P.R. Campagna, Application of field portable X-ray fluorescence spectrometers for field screening air monitoring filters for metals, J. Hazard. Mater. 43 (1995) 91-99.

[16] D.J. Kalnicky, T.D. Moustakas, Determination of argon in sputtered silicon films by energy-dispersive X-ray fluorescence spectrometry, Anal. Chem. 53 (12) (1981) 1792-1795.

[17] P.A. Pella, The Development of Potential Thin Film Standards for Calibration of X-Ray Fluorescence Spectrometers, EPA-600/7-80-123, NIST PB80-220239, June 1980.

[18] Standard Reference Materials Catalog, NIST Special Publication 260, National Institute of Standards and Technology, Gaithersburg, MD, SRM Quarterly, Summer 1999 and Winter 2000, National Institute of Standards and Technology, Gaithersburg, MD.

[19] Leaded Film Standards with Certified Lead Levels for XRF Testing and Test Kit Applications, QuanTech, Rosslyn, VA.

[20] M. Bernick, D.J. Kalnicky, Activities Report: Measurement of NIST Standard Reference Materials with Spectrace 9000 Field Portable XRF Analyzers — May 1993, ERT/REAC, 5/19/93.

[21] Federal Register, Definition and Procedure for the Determination of the Method Detection Limit, Appendix B to Part 136, 49 (no. 209), 1984, pp. 198-199.

[22] S. Shefsky, Comparing Field-Portable X-Ray Fluorescence (XRF) to Laboratory Analysis of Heavy Metals in Soil, NITON Corporation, Billercia, MA, 1996.

[23] C.M. Andreas, W.A. Coakley, in: Proceedings of the Research and Development '92 Conference on X-Ray Fluorescence Spectrometry: Uses and Applications at Hazardous Waste Sites, Hazardous Materials Research Control Institute, San Francisco, CA, February 1992.

[24] M. Bernick, M. Sprenger, D. Idler, D. Miller, J. Patel, L. Kaelin, G. Prince, An evaluation of field portable XRF soil preparation methods, in: Proceedings of the 2nd International Symposium on Field Screening Methods for Hazardous Wastes and Toxic Chemicals, EPA-600-9-91-028, NIST PB92-12574, December 1991.

[25] US EPA/ERT, QA/QC Guidance for Removal Program Activities - Sampling QA/QC Plan and Data Validation Procedures, April 1990 (OSWER Directive 9360.4-01).

[26] US EPA, Office of Emergency and Remedial Response, Data Quality Objectives Process for Superfund Interim Final Guidance, September 1993 (Publication 9355.01). 
[27] D.J. Kalnicky, J.M. Soroka, R. Singhvi, G. Prince, XRF analyzers, field-portable, in: R.A. Meyers (Ed.), Encyclopedia of Environmental Analysis and Remediation, Vol. 8, Wiley, New York, 1998, pp. 5315-5342, ISBN 0-471-11708-0.

[28] US EPA/ERT, Representative Sampling Guidance, Volume 1 - Soil, November 1991 (OSWER Directive 9360.4-10).

[29] D.J. Kalnicky, J. Patel, R. Singhvi, Factors affecting comparability of field XRF and laboratory analyses of soil contaminants, in: Proceedings of the Forty-First Annual Conference on Applications of X-Ray Analysis, Colorado Springs, CO, August 1992.

[30] D. Kalnicky, Effects of Thickness Variations on XRF Analyses of Soil Samples When Using Plastic Bags as Measurement Containers, US EPA Contract no. 68-03-3482, 13 March 1992.

[31] M.B. Bernick, G. Prince, R. Singhvi, D.J. Kalnicky, in: Proceedings of the Petro-Safe '94 Conference on the Use of Field-Portable X-Ray Fluorescence Instruments to Analyze Metal Contaminants in Soil and Sediment, Penn-Well Conferences \& Exhibitions, Houston, Book II, Vol. VI, 1994, pp. 195-204.

[32] C.A. Kuharic, W.H. Cole, A.K. Singh, D. Gonzales, US EPA/EMSL, An X-Ray Fluorescence Survey of Lead Contaminated Residential Soils in Leadville, Colorado: A Case Study, March 1993 (EPA/600/R-93/073).

[33] J.S. Kean, Reference Materials, American Laboratory, October 1993.

[34] National Research Council Canada, Institute for Environmental Chemistry, Halifax, NS, Canada.

[35] R.O. Gilbert, Statistical Methods for Environmental Pollution Monitoring, Van Nostrand, New York, 1987.

[36] N. Draper, H. Smith, Applied Regression Analysis, 2nd Edition, Wiley, New York, 1981.

[37] R.P. Swift, Evaluation of a field-portable X-ray fluorescence spectrometry method for use in remedial activities, Spectroscopy 10 (6) (1995).

[38] L. Fluk, B. Hooker, J. Pfeil, In situ X-ray fluorescence analysis at a mine site, in: Proceedings of the First International Conference on Tailings and Mine Waste '94, Ft. Collins, CO, January 1994, A.A. Balkema Publishers, Brookfield, VT, pp. 119-125.

[39] US EPA, Environmental Technology Verification Report, Field Portable X-Ray Analyzer: Scitec MAP Spectrum Analyzer, EPA/600R-97/147, March 1998; NITON XL Spectrum Analyzer, EPA/600R-97/150, March 1998; Metorex X-MET 920 MP, EPA/600R-97/151, March 1998; Spectrace TN 9000 and TN Pb Field Portable X-Ray Fluorescence Analyzers, EPA/600R-97/145, March 1998; Metorex X-MET 920-P and 940, EPA/600R-97/146, March 1998.

[40] US EPA/ERT, SOP 1713, Spectrace 9000 Field Portable X-Ray Fluorescence Operating Procedure, May 1999.

[41] Office of Solid Waste and Emergency Response, US EPA, Test Methods for Evaluating Solid Waste, 3rd Edition, Update 3, SW-846, December 1996; Field Portable X-Ray Fluorescence Spectrometry for the Determination of Elemental Concentrations in Soil and Sediment, Method 6200, Revision 0, January 1998.

[42] S. Piorek, J.R. Passmore, B.D. Lass, J. Koskinen, New developments in lead in paint analysis with field portable X-ray fluorescence analyzer, in: Proceedings of the American Chemical Society Symposium on Lead Poisoning in Children: Exposure, Abatement, and Program Issues, Washington, DC, August 1992.

[43] L. Grodzino, C. Parsons, D. Sackett, S. Shefsky, B. Tannian, A New XRF Method for Measuring Lead in Paint, in: Proceedings of an International Symposium on Field Screening Methods for Hazardous Wastes and Toxic Chemicals, VIP-47, Vol. 2, Air and Waste Management Association, Pittsburgh, PA, 1995, pp. 1118-1132.

[44] ASTM Standards on Lead Hazards Associated with Buildings, American Society for Testing and Materials, Philadelphia, PA, September 1998, ASTM Stock no. LEAD1, ISBN 0-8031-2590-9.

[45] H.A. Vincent, D.C. Boyer, Quality assurance considerations in the analysis for lead in urban dust by energy dispersive X-ray fluorescence, in: Proceedings of the 1992 US EPA/A\&WMA International Symposium on Measurement of Toxic and Related Air Pollutants, Air and Waste Management Association, Pittsburgh, PA, EPA Report no. EPA/600/R-92/131, 1992, pp. 796-801.

[46] A Field Test of Lead-Based Paint Testing Technologies: Technical Report, EPA 747-R-95-002b, May 1995.

[47] K. Ashley, M. Hunter, L.H. Tait, J. Dozier, L. Seaman, P.F. Berry, Field investigation of on-site techniques for the measurement of lead in paint films, Field Anal. Chem. Technol. 2 (1) (1998) 39-50.

[48] T. Sumitra, S. Kongsombatsuk, Determination of manganese in airborne particulates in a dry-cell battery factory using X-ray fluorescence technique, in: Biological Trace Element Research, Humanae Press, Clifton, UK, 1990, pp. 269-277.

[49] R. Philips, P. Greenlaw, R.J. Bath, Trace lead in aqueous samples, Environ. Testing Anal. November/December (1993) 34-39. 
[50] N.A. Wogman, K.K. Nielson, Development and application of an in situ X-ray fluorescence spectrometer for underwater sediment analysis, Environ. Int. 4 (1980) 313-324.

[51] M.O. Stallard, S.E. Apitz, C.A. Dooley, X-ray fluorescence spectrometry for field analysis of metals in marine sediments, Poll. Bull. 31 (4-12) (1995) 297-305.

[52] T.W. Packer, Determination of the concentration of uranium in soil and stream sediment samples using a high resolution energy-dispersive X-ray fluorescence analyzer, Int. J. Appl. Radiat. Isot. 34 (1) (1983) 273-281.

[53] J.C. Morley, C.S. Clark, J.A. Deddens, K. Ashley, S. Roda, Evaluation of a portable X-ray fluorescence instrument for the determination of lead in workplace air samples, Appl. Occup. Environ. Hyg. 14 (1999) 306-316.

[54] B.N. Bero, M.C. von Braun, C.R. Knowles, J.E. Hammel, The use of X-ray fluorescence to detect lead contamination of carpeted surfaces, Environ. Monitor. Assess. 27 (1993) 17-33.

[55] A.M. Saaco, J. Bass, Application of a portable XRF instrument for field measurement of lead on TSP filters, in: Proceedings of the Eighth International Conference on On-Site Analysis — the Lab Comes to the Field, Lake Las Vegas, NV, January 2000.

[56] D.W. Sackett, Evaluation of a Field-Portable X-Ray Fluorescence Analyzer for Department of Energy Application, NITON Corporation, Billercia, MA, July 1996. 